\title{
Acúmulo de metais PeSAdos e CAPACIDADE de IMPERMEABILIZAÇÃO DO SOLO IMEDIATAMENTE ABAIXO DE UMA CÉLULA DE UM ATERRO DE RESÍDUOS SÓLIDOS
}

\section{HEAVY METALS ACCUMULATION AND SOIL IMPERMEABILIZATION CAPACITY DIRECTLY BELOW OF A MUNICIPAL SOLID WASTE LANDFILL}

\begin{abstract}
FERNANDO JORGE SANTOS OLIVEIRA
Engenheiro Químico (UFPE), Mestre em Ciências em Tecnologia de Processos Químicos e Bioquímicos (EQ/UFRJ), Doutorando do Programa de Tecnologia de Processos Químicos e Bioquímicos (EQ/UFRJ)
\end{abstract}

\section{JOSÉ FERNANDO THOMÉ JUCÁ}

Engenharia Civil, Mestre em Ciências em Engenharia Civil (COPPE/UFRJ), Doutor em Ciências em Engenharia Civil (Universidad Politécnica de Madri), Professor da Graduação e da Pós-graduação do Deparamento de Engengenharia Civil da Universidade Federal de Pernambuco (UFPE)

Recebido: 09/10/03 Aceito: 16/07/04

\section{RESUMO}

Estudos sobre a contaminação de solos e seus mecanismos são cada vez mais explorados devido a necessidade de segurança a longo prazo exigida para sistemas de contenção de resíduos. Neste sentido, investigou-se o acúmulo de alguns metais pesados, a capacidade de impermeabilização do solo imediatamente abaixo de uma célula do Aterro de Resíduos Sólidos da Muribeca, e as características físico-químicas do percolado. Os perfis de concentração dos metais pesados e de sólidos voláteis no solo mostraram que existe uma frente de contaminação em direção ao fundo, evidenciando-se também que ocorre ampla faixa de concentração dos metais analisados, relacionada à concentração de cada espécie no percolado. O Chumbo, o Cobre e o Manganês foram os metais preferencialmente sorvidos e apresentaram uma velocidade média de frente de saturação de $2,3 \times 10^{-2} \mathrm{~m} / \mathrm{ano}$, que indica transporte por advectivo-dispersivo, em desacordo com a textura do solo.

PALAVRAS-CHAVE: Contaminação, solo, metais pesados, resíduos sólidos urbanos.

\begin{abstract}
Studies concerning soil contamination and their mechanisms have been explored more and more due to the long term security requirements demanded for residue containment systems. In this sense, the accumulation of some heavy metals, the impermeabilization capacity of the soil directly below a cell of the solid waste landfill of the Muribeca county, and the physicochemical characteristics of the leachate were investigated. Concentration profiles of heavy metals and volatile solids in the soil indicated the existence of a contamination plume towards the bottom, also showing occurrence of a wide range of concentrations of the analyzed metals, related to the concentration of each species in the leachate. Preferentially, Lead, Copper and Manganese were the absorbed metals and they presented a mean saturation velocity of the plume of $2.3 \times 10^{-2} \mathrm{~m} / \mathrm{year}$, indicating an advective-dispersive transport, in disagreement with the soil texture.
\end{abstract}

KEYWORDS: Contamination, soil, heavy metals, municipal solid waste.

\section{INTRODUÇÃO}

A disposição inadequada de resíduos no solo e nas águas superficiais é reconhecida como um dos graves problemas da atualidade. Os efeitos do lançamento de rejeitos na natureza são incalculáveis e recaem principalmente na escassez, na contaminação da água, e no aumento das doenças associadas à poluição ambiental. Entre as técnicas para tratamento e disposição final de resíduos sólidos urbanos (RSU), aterros controlados e aterros sanitários, estão entre as que apresentam me- nor relação de custo, especialmente quando se dispóe de áreas apropriadas. Nestes processos de disposição final, ocorre a decomposição do material originalmente disposto devido à ação da microbiota nativa, tanto em aerobiose, que ocorre nas regiōes mais superficiais das células de confinamento, quanto em anaerobiose, estabelecida nas regiōes mais profundas. Como produto da biodeterioração dos resíduos e somado à água infiltrada nas células, forma-se o líquido chamado de chorume ou percolado. As características físico-químicas e microbiológicas do percolado são função da composição, origem e idade dos resíduos originalmente dispostos, bem como da fase de decomposição do processo. De forma geral, este líquido contém, em concentraçōes variadas, compostos orgânicos polares, apolares, além de metais pesados que podem contaminar o meio ambiente e ser tóxicos aos seres vivos (Palmisano \& Barlaz, 1996; Yasuhara et al., 1997).

Sistemas de impermeabilização são requeridos para a confecção de aterros de RSU devido ao elevado potencial poluente do percolado, e ao fato de minimizarem 
a contaminação ambiental. Em geral, estes sistemas são constituídos de mantas impermeáveis associadas a camadas de solo compactado, de formaçōes naturais argilosas, ou formado apenas por camadas de solos argilosos compactados. As mantas de impermeabilização são caras e oneram o custo de confecção das células dos aterros. Por outro lado, os solos argilosos aparecem como uma alternativa barata e eficiente para impermeabilização superior, lateral e de fundo.

O Aterro de Resíduos Sólidos (ARS) da Muribeca é o maior sítio de disposição e tratamento de resíduos sólidos da região metropolitana de Recife, Pernambuco. A área de $600.000 \mathrm{~m}^{2}$ localiza-se a cerca de $15 \mathrm{~km}$ ao sul da cidade de Recife, e recebe diariamente 2.800 toneladas de resíduos urbanos, hospitalares e industriais.

Desde 1986, o local funcionava como depósito de lixo a céu aberto. No ano de 1994 foi iniciado um processo de tratamento e recuperação ambiental da área degradada, que objetivava a transformação do lixão em um aterro celular controlado. Para isso, os estudos ambientais realizados envolveram levantamentos de dados topográficos, hidro- geológicos, climáticos, geológicos e geotécnicos, auxiliando o estabelecimento dos critérios a serem adotados para a remediação do local e tratamento dos resíduos. Os resultados destes estudos serviram como base para a escolha da técnica de aterro celular controlado para o local da Muribeca (Jucá et al., 1996).

Posteriormente na área do aterro, ocorreu a confecção de duas células experimentais de aproximadamente $150 \mathrm{~m} \times 200 \mathrm{~m} \times 20 \mathrm{~m}$ de altura, construídas de maneira seqüencial, viabilizando o tratamento isolado em cada uma. As células de confinamento foram dotadas de piezômetros para coleta de líquido, de tubulações para canalização e queima dos gases originados pela biodegradação do lixo, bem como de sistemas de impermeabilização lateral e de topo. No entanto, optou-se pela manutenção dos resíduos sobre o solo natural, considerando que os aspectos geológicos do terreno aliados a algumas caraterísticas geotécnicas do solo eram suficientes para a impermeabilização de fundo. Cabe ressaltar ainda a inviabilidade técnica e econômica enfrentada na época, referente à opção da prévia remoção do elevado montante de lixo do local para construção do sistema de impermeabilização de fundo, cerca de 5.000.000 de toneladas com altura variando de 10 a $70 \mathrm{~m}$.
Este trabalho apresenta o perfil de acúmulo de metais pesados no solo de fundo de uma célula do referido aterro, realizado quatorze anos após a disposição inicial do lixo no local. Também são apresentados os estudos concernentes à condutividade hidráulica do solo, investigando sua potencialidade como agente de impermeabilização, assim como os dados da monitorização de alguns parâmetros físico-químicos do percolado durante o período.

\section{METODOLOGIA}

Os dados apresentados neste trabalho referem-se ao percolado oriundo da Célula 02 e do solo imediatamente inferior a ela. As Figura 1 e 2 apresentam, respectivamente, a localização da célula no aterro e os seus detalhes.

A fim de se verificar as características físico-químicas do contaminante, retirou-se amostras de percolado oriundo de piezômetros pré-instalados e do líquido obtido durante as sondagens. Para tal, empregou-se amostradores tipo caneca de aproximadamente $0,8 \mathrm{~m}$ de altura com 0,05 m de diâmetro. As amostras de líquidos foram acondicionadas em recipientes plásticos, resfriadas a $4^{\circ} \mathrm{C}$ e encaminhadas aos Laboratórios de Engenharia Ambiental e de Controle da Qualidade do Departamento de Engenharia Química da UFPE para as análises de rotina de parâmetros de qualidade de efluentes. Os ensaios para determinação das concentrações dos elementos químicos foram executados no Laboratório de ICP, Departamento de Geologia da UFPE. Todos os ensaios físico-químicos foram executados de acordo com as recomendações de APHA (1992).

A segunda etapa foi a obtenção das amostras de solo de fundo do aterro. $\mathrm{O}$ emprego de sondagens à percussão, SPT, viabilizou a retirada de amostras do solo imediatamente abaixo do lixo confinado na Célula 02. As amostras foram originadas na região mais profunda da célula e compreendiam cilindros com $1,5 \mathrm{~m}$ de altura e com aproximadamente $0,06 \mathrm{~m}$ de diâmetro. Cada uma delas foi então subseqüentemente dividida em pequenos corpos de provadeaproximados $0,05 \mathrm{~m}$ de altura. Por sua vez estes foram transferidos para sacos plásticos dotados de vedação e resfriados a $4^{\circ} \mathrm{C}$ em recipientes térmicos até os imediatos procedimentos de análise.

Para cada corpo de prova foram determinados o $\mathrm{pH}$ e os teores de umidade, sólidos voláteis, Sódio, Cálcio, Ferro, Cromo, Alumínio, Chumbo, Cobre e Manganês. As determinações dos teores de umidade, de sólidos voláteis e do $\mathrm{pH}$ foram executadas segundo WHO (1979). Para analisar as concentraçōes dos metais sorvidos pelo solo, utilizou-se o procedimento descrito por Tessier $\mathrm{et} \mathrm{al}$. (1979). Este processo consistiu na secagem das amostra em estufa a $105 \pm 2{ }^{\circ} \mathrm{C}$ até peso constante, e, posteriormente, na cominuição a pó em um moinho de bolas revestido com Carbeto de Tungstênio, suspensão em solução $1 \mathrm{M}$ de Cloreto de Magnésio e análise do sobrenadante em um espectrômetro de plasma induzido (ICP/AES), modelo Iris/AP - TJA, equipado com detetor de estado sólido (CIO).

A caracterização geotécnica do solo ocorreu no Laboratório de Solos e Instrumentação da UFPE e constou da determinação da granulométrica com peneiramento seguido de sedimentação de acordo com ABNT (1984a). Os ensaios para determinação dos limites de liquidez e de plasticidade foram executados segundo ABNT (1984b; 1994c), respectivamente. As determinações das superfícies específicas foram executadas de acordo com Pejon (1992). Os ensaios para determinação do coeficiente de condutividade hidráulica à água foram determinados in situ, conduzidos utilizando-se o método de infiltração direta, e em laboratório por meio de um permeâmetro de paredes flexíveis acoplado a um Sistema Triflex 2.

\section{RESULTADOS E DISCUSSÃO}

\section{Características gerais do percolado e do solo}

O percolado do Aterro da Muribeca é um líquido escuro de composição química e microbiológica variada. A Tabela 1 apresenta os resultados dos testes físicoquímicos realizados nas amostras do chorume.

Durante a investigação, observouse clara estratificação de cor e variação de composição química, do líquido oriundo dos piezômetros. Além disso, a análise dos dados da Tabela 1 permite ainda verificar que as concentrações dos vários parâmetros analisados aumentaram com a profundidade. Este fato está provavelmente relacionado com a infiltração de águas de chuva pela camada de cobertura das células, o que permite maior diluição do líquido originado pela decomposiçāo dos 


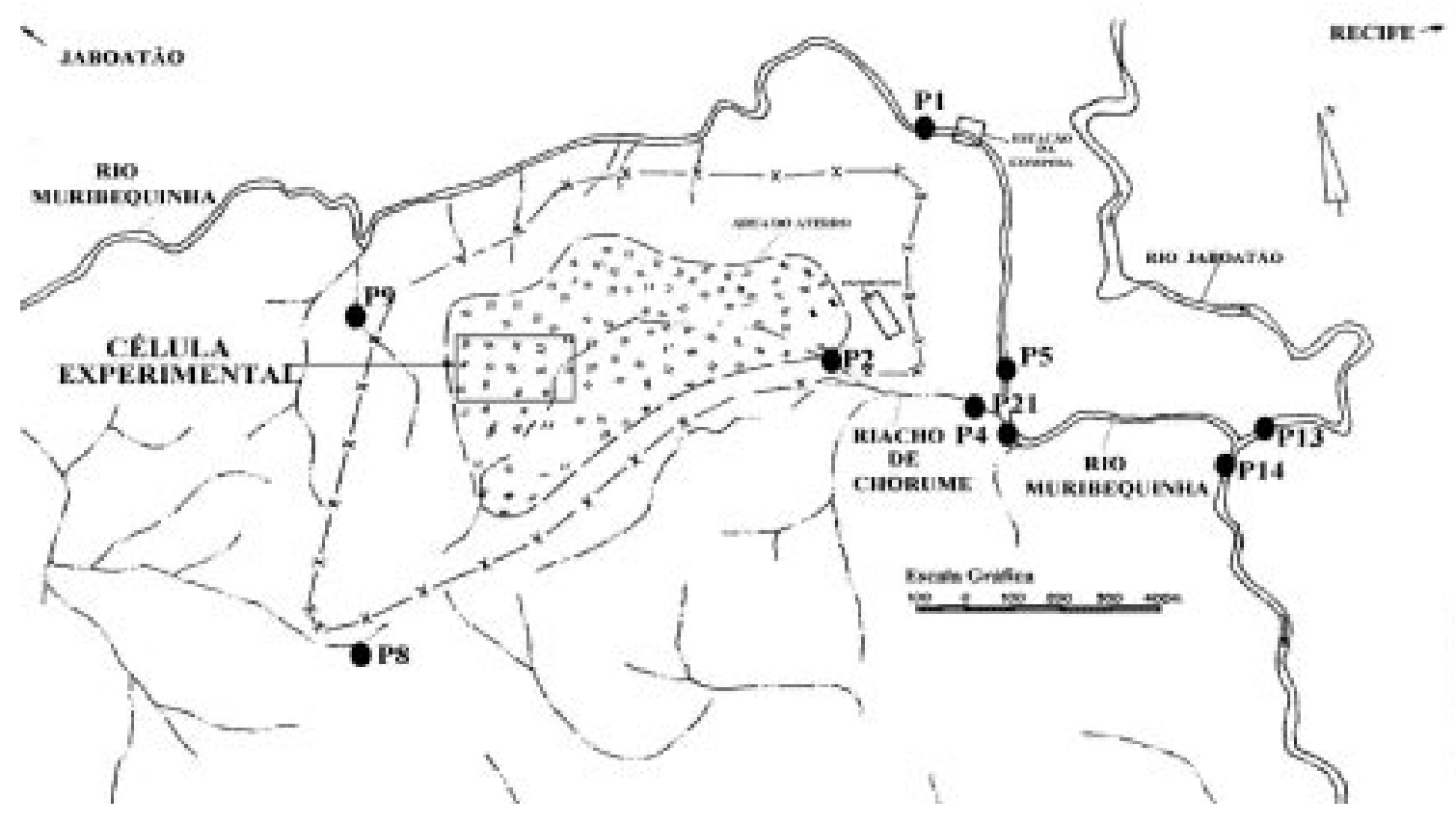

Figura I- Localização da célula 02 no ARS da muribeca

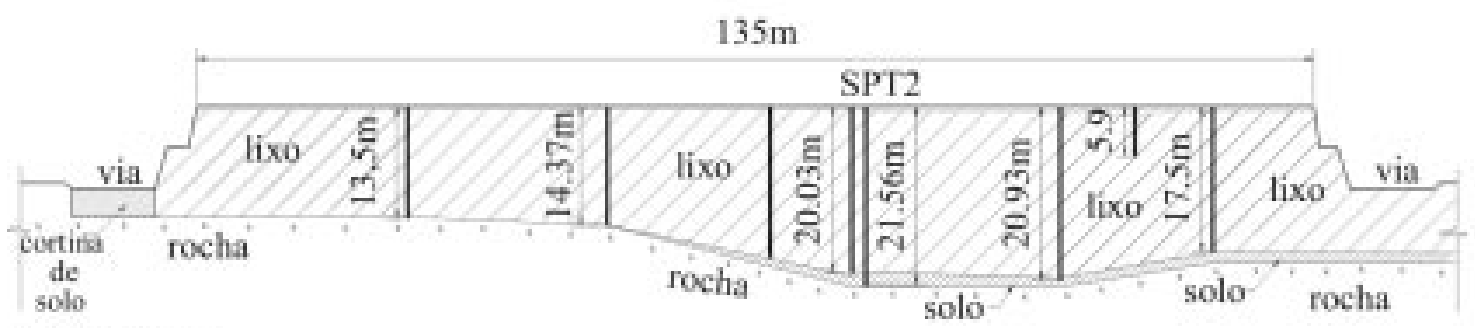

CORTE AB

Legenda:

SPT

SONDAGEM Ȧ PERCUSSĀO

Figura 2 - Perfil da célula 02 do ARS da Muribeca

resíduos dispostos nas partes mais superficiais da célula. De fato, Jucá \& Maciel (1999) evidenciaram que a camada de topo da célula chega a apresentar regiôes com coeficiente de permeabilidade à água de $4 \times 10^{-6} \mathrm{~cm} / \mathrm{s}$. Este valor é elevado e não recomendado por Daniel (1993) para confecção de sistemas de impermeabilização, pois permite alta taxa de infiltração, aumentando assim, o gradiente de pressão no interior da célula que é determinante para o transporte mecânico-advectivo de espécies através de solos.

O percolado apresentou valores de pH entre 7,0 e 8,3 com alcalinidade va- riando entre 2.200 a $12.480 \mathrm{mg} / \mathrm{L}$ de $\mathrm{CaCO}_{3}$, revelando que o líquido é predominantemente alcalino. Estes valores são relatados por Palmisano \& Barlaz (1996) como característicos de percolados de resíduos em fase metanogênica de degradação. Na metanogênesis, ocorre aumento na concentrações de bactérias metanogênicas que degradam os ácidos graxos livre e de cadeia carbônica curta originados na acidogênesis, promovendo a formação de metano e conseqüente elevação de $\mathrm{pH}$ e alcalinidade do percolado (Chian \& DeWalle, 1976). Estudos cromatográficos realizados por Jucá
\& Maciel (1999) em amostras de biogás revelaram resultados típicos de metanogênesis.

Os elevados teores de cloretos variam de 580 a $4.800 \mathrm{mg} / 1 \mathrm{de} \mathrm{Cl}$, assim como ocorre com o Sódio e o Cálcio, indicam que estes são os íons mais abundantes no percolado. A acentuada presença de íons cloreto, Sódio e Cálcio está provavelmente relacionada à elevada solubilidade apresentada pela maioria dos sais que contém estes elementos (Leprevost, 1975), facilitando o processo de solubilização e/ou de lixiviação.

Os valores de demanda bioquímica de oxigênio (DBO) de 200 a 5.000 mg/L 
Tabela I - Resultados dos ensaios físico-químicos realizados nas amostras do percolado do ARS da Muribeca como função da profundidade de amostragem

\begin{tabular}{ccc}
\hline Parâmetro & \multicolumn{2}{c}{ Resultado em funçáo da profundidade } \\
& de 1 a $3 \mathrm{~m}$ & $>3 \mathrm{~m}$ \\
\hline $\mathrm{pH}$ & $7-8,3$ & $7-8,3$ \\
Alcalinidade $\left(\mathrm{mg} / \mathrm{L}\right.$ de $\left.\mathrm{CaCO}_{3}\right)$ & $2.220-5.600$ & $4.750-12.480$ \\
Cloretos $(\mathrm{mg} / \mathrm{L} \mathrm{Cl})$ & $580-1.700$ & $1.500-4.800$ \\
$\mathrm{DQO}\left(\mathrm{mg} / \mathrm{L}\right.$ de $\left.\mathrm{O}_{2}\right)$ & $500-4.000$ & $3.000-16.000$ \\
$\mathrm{DBO}\left(\mathrm{mg} / \mathrm{L} \mathrm{de} \mathrm{O}_{2}\right)$ & $200-2.170$ & $1.750-6.000$ \\
Sódio* & $420-1.500$ & $1.000-3000$ \\
Cálcio* & $20-105$ & $30-1.700$ \\
Alumínio* & $24-500$ & $50-1.800$ \\
Ferro* $^{*}$ & $15-220$ & $30-770$ \\
Cobre* $^{*}$ & $0,2-2,9$ & $0,2-4,4$ \\
Cromo* $^{*}$ & $<0,01-3,5$ & $<0,01-6,9$ \\
Chumbo* $^{*}$ & $<0,01-1,5$ & $<0,01-1,8$ \\
Manganês* $^{*}$ & $<0,01-35$ & $<0,01-19$ \\
\hline
\end{tabular}

Nota: ${ }^{*}$ valor expresso em mg/L do elemento

de $\mathrm{O}_{2}$ e de 500 a $16.000 \mathrm{mg} / \mathrm{L}$ de $\mathrm{O}_{2}$ para a de demanda química de oxigênio (DQO) indicam a potencial carga orgânica do líquido. Verifica-se que os valores de DQO foram sempre duas a três vezes superiores aos de $\mathrm{DBO}$, o que pode estar relacionado à presença de materiais com baixa biodegradabilidade. Estes resultados corroboram os apresentados por Harmsen (1983), que identificou a presença de compostos com baixa biodegradabilidade, como ácido fúlvico, húmico e tânico, em amostras de percolados oriundos de um aterro de resíduos sólidos em metanogênesis.

O Ferro e o Alumínio foram os metais pesados mais concentrados no percolado. Este fato reforça a hipótese de lixiviação do solo de cobertura das células, ocasionada pela permeação de água de chuva. Pode-se também relacionar a presença acentuada destes elementos à corrosão e/ou biodeterioração de materiais confinados, como peças metálicas.

Os valores das faixas de concentração dos outros metais pesados analisados confirmam a disposição de materiais provenientes das industrias, aumentando a recalcitrância do percolado. Genetelli \& Cirello (1976), USEPA (1975) e, mais recentemente, Kuajara et al. (1997) apre- sentaram resultados de concentração de vários metais pesados em percolados de aterros de resíduos sólidos urbanos. Estes autores também observaram larga faixa de variação nos valores de concentração dos metais pesados, porém em cifras muito inferiores. Adicionado a este fato, verificou-se maiores concentraçôes dos metais pesados nos percolados oriundos das maiores profundidades. Esta é uma preocupação a mais devido à promoção de um elevado gradiente de concentração na interface do solo com o lixo, que é a força motriz do transporte difusivo em meios porosos (Welty et al. 1994).

Os resultados apresentados no presente trabalho alertam para a problemática da disposição conjunta de resíduos urbanos e industriais

A textura do solo de fundo da célula é de solo fino, classificado segundo a USC (Unified Soil Classification) como $\mathrm{CL}$, argila arenosa. A granulometria consta de $32 \%$ de argila, $26 \%$ de silte, $27 \%$ de areia fina e $15 \%$ de areia média. O limite de liquidez encontrado foi de $37,8 \%$, o índice de plasticidade de $18,6 \%$ e a superfície específica de $64 \pm 4 \mathrm{~m}^{2} / \mathrm{g}$. A sondagem indicou que a compacidade do solo varia entre baixa e media. Abaixo da camada de solo, de profundidade varian- do desde afloramento de rocha a um metro e meio, encontra-se uma rocha calcárea. Esta rocha se estende por toda a área do aterro em associaçôes com rochas gnaisses formando um embasamento cristalino, (Jucá et al. 1998). In situ, observouse que o solo apresentou condutividade hidráulica à água de $2 \pm 0,8 \times 10^{-10} \mathrm{~cm} / \mathrm{s}$. Estes valores são muito baixos, o que é desejável para impermeabilizar o aterro, mas não são compatíveis com a distribuição granulométrica da amostra. Estes baixos valores podem estar relacionados com a deposição de finos durante a execução dos ensaios e/ou com a redução dos vazios do solo promovida pelo crescimento microbiano às custas da matéria orgânica, impulsionando a execução de ensaios em laboratório. A condutividade hidráulica de amostra de solo indeformada à água foi de $1 \pm 0,5 \times 10^{-9} \mathrm{~cm} / \mathrm{s}$, que é adequada para materiais a serem utilizados para contenção de resíduos (Daniel, 1993). Este valor é uma ordem de grandeza maior que os valores encontrados no campo, revelando a provável deposição de finos durante a condução dos ensaios in situ. De fato, em campo fica inviável ter o controle sobre a qualidade da água, afim de que ela apresente baixo teor de sólidos suspensos. Em geral, a água apresenta presença de solo suspenso que pode formar depósitos na base do tubo de ensaio, reduzindo a permeabilidade. No entanto, cabe destacar ainda que os valores da permeabilidade do solo obtidos nos testes de laboratório são muito baixos. Isto reforça a hipótese de redução dos vazios do solo promovida pelo crescimento microbiano, corroborando os resultados apresentados por Ruhl \& Daniel (1997) que evidenciaram a redução de permeabilidade de geosintéticos quando permeado com chorume natural.

\section{Perfis da contaminação}

Para investigar de forma indicativa o alcance da frente de contaminação orgânica no subsolo do Aterro da Muribeca, foi traçado o perfil de sólidos voláteis do solo. O método baseia-se na ignição da amostra e é recomendado tanto para solos quanto para resíduos ou húmus, no entanto, para execução deste ensaio, devese partir de amostras secas em estufa até peso constante. A partir desta necessidade, os dados de umidade também foram obtidos. O perfil de umidade em conjunto com o de teor de sólidos voláteis e de $\mathrm{pH}$ estão apresentados na Figura 3.

Verifica-se que o solo apresentou maiores valores de umidade, sólidos volá- 
teis e $\mathrm{pH}$ nos primeiros $50 \mathrm{~cm}$ de profundidade, a partir da interface entre $o$ lixo e o solo. Em áreas não contaminadas do aterro os valores típicos de teor de sólidos voláteis e de $\mathrm{pH}$ não são superiores a $2 \%$ e 4,5 , respectivamente, indicando a contaminação orgânica do subsolo até a profundidade de $0,5 \mathrm{~m}$.

As Figura 4 e 5 apresentam os perfis da concentração dos metais investigados.

Todos os perfis apresentam clara frente de contaminação em direção ao fundo, sendo o formato das curvas obtidas para alguns dos elementos são semelhantes às formas apresentadas por Quigley et al. (1987) na investigação da contaminação de uma argila siltosa localizada abaixo de um aterro de resíduos sólidos urbanos em Sarnia, Canadá.

O solo apresentou um teor máximo de Cálcio sorvido de $2.800 \mathrm{mg} / \mathrm{kg}$, maior que o teor máximo de Sódio, de aproximadamente $700 \mathrm{mg} / \mathrm{kg}$. A análise conjunta dos dados da Tabela 1 e da Figura 4 revela que, embora a concentração de Sódio no percolado seja superior a do Cálcio, este último foi preferencialmente sorvido pelo solo, corroborando as alegaçôes de Mitchell (1993) sobre a preferencial sorção de elementos de maior carga eletrônica. A análise geral dos perfis de concentração dos metais pesados apresentados na Figura 5 permite verificar uma ampla faixa de variação nas concentraçôes destes elementos, porém sua distribuição em função da profundidade é semelhante. Observa-se uma região mais concentrada com os elementos analisados, que se inicia na interface do lixo com o solo, $0 \mathrm{~m}$, e se estende até a profundidade de 0,4 m. Após esta região, surge uma outra, caracterizada por uma gradual redução dos valores de concentração, que se inicia aos aproximados $0,2 \mathrm{~m}$ e se estende até $0,8 \mathrm{~m}$. A partir desta camada, verifica-se uma terceira região, de $0,8 \mathrm{~m}$ a $1,5 \mathrm{~m}$, onde são observados os mais baixos valores de concentração. Cabe destacar que nesta última região ocorre constância nos resultados de concentração de metais sorvidos pelo solo.

Uma análise mais detalhada da Figura 5 permite constatar que o Ferro e Alumínio foram os metais mais acumulados pelo solo, alcançando valores de aproximadamente $4.000 \mathrm{mg}$ do elemento por quilograma de solo. Os dados da Tabela 1 permitem verificar que estes elementos são os metais mais abundantes no percolado, e, portanto, mais abundante no solo. Após a profundidade de $0,8 \mathrm{~m}$, observa-se constância nos valores de con-
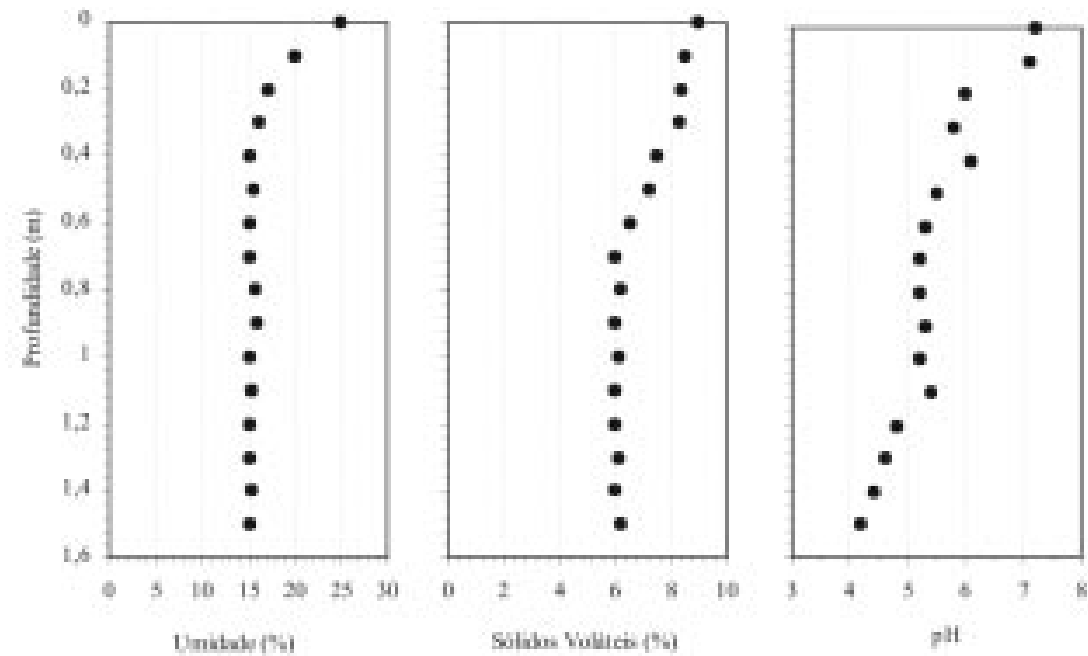

\section{Figura 3 - Perfis dos teores umidade, sólidos voláteis e do pH do solo imediatamente inferior à Célula 2 do ARS da Muribeca}
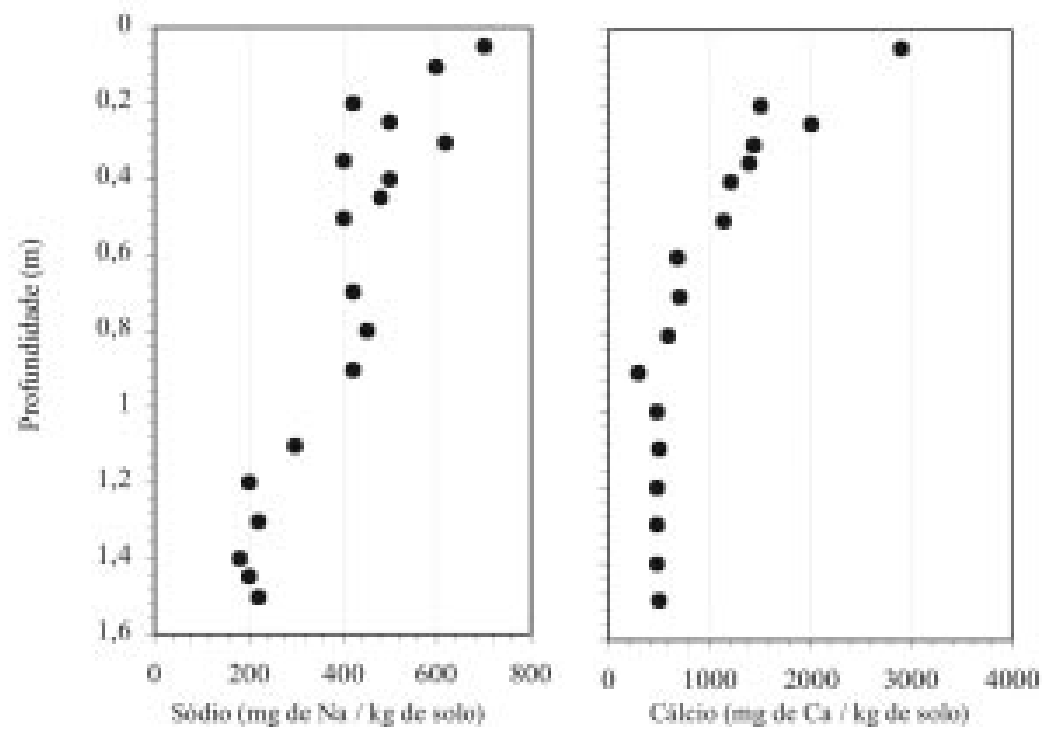

Figura 4 - Perfis do acúmulo de Sódio e de Cálcio no solo imediatamente inferior à Célula 2 do ARS da Muribeca

centração desses metais, alcançando os valores de base, em torno de $1500 \mathrm{mg} / \mathrm{kg}$ e $200 \mathrm{mg} / \mathrm{kg}$ respectivamente para o Alumínio e Ferro.

O solo apresentou menores concentraçôes de Chumbo, Cobre e Cromo. Na regiāo de saturação, o Cobre apresentou um valor máximo de concentração de aproximadamente $22 \mathrm{mg} / \mathrm{kg}$, o Chumbo, $10 \mathrm{mg} / \mathrm{kg}$ e o Cromo $5 \mathrm{mg} / \mathrm{kg}$, que são baixos quando comparados com os valores observados para o Ferro e Alumínio. No entanto, a análise conjunta destes dados com os resultados apresentados na Tabela 1 permite verificar que ocorre menor acumulação relativa em virtude dos menores valores de concentração des- tes metais no percolado. Fica então evidenciado que existe uma relação direta entre a concentração de metal sorvido no solo e a sua concentração no percolado. Observa-se também o alcance da frente de contaminação por Chumbo, Cromo e Cobre, que corresponde a uma velocidade média da frente de saturação de $2,3 \times 10^{-2} \mathrm{~m} /$ ano. Este resultado indica que os metais com menor velocidade de migração através do solo são transportados por um mecanismo advectivodispersivo (Shakelford \& Redmond, 1995), não corroborando as alegações apresentadas por Jessberger (2000) sobre transporte predominantemente difusivo de contaminantes através do solo 

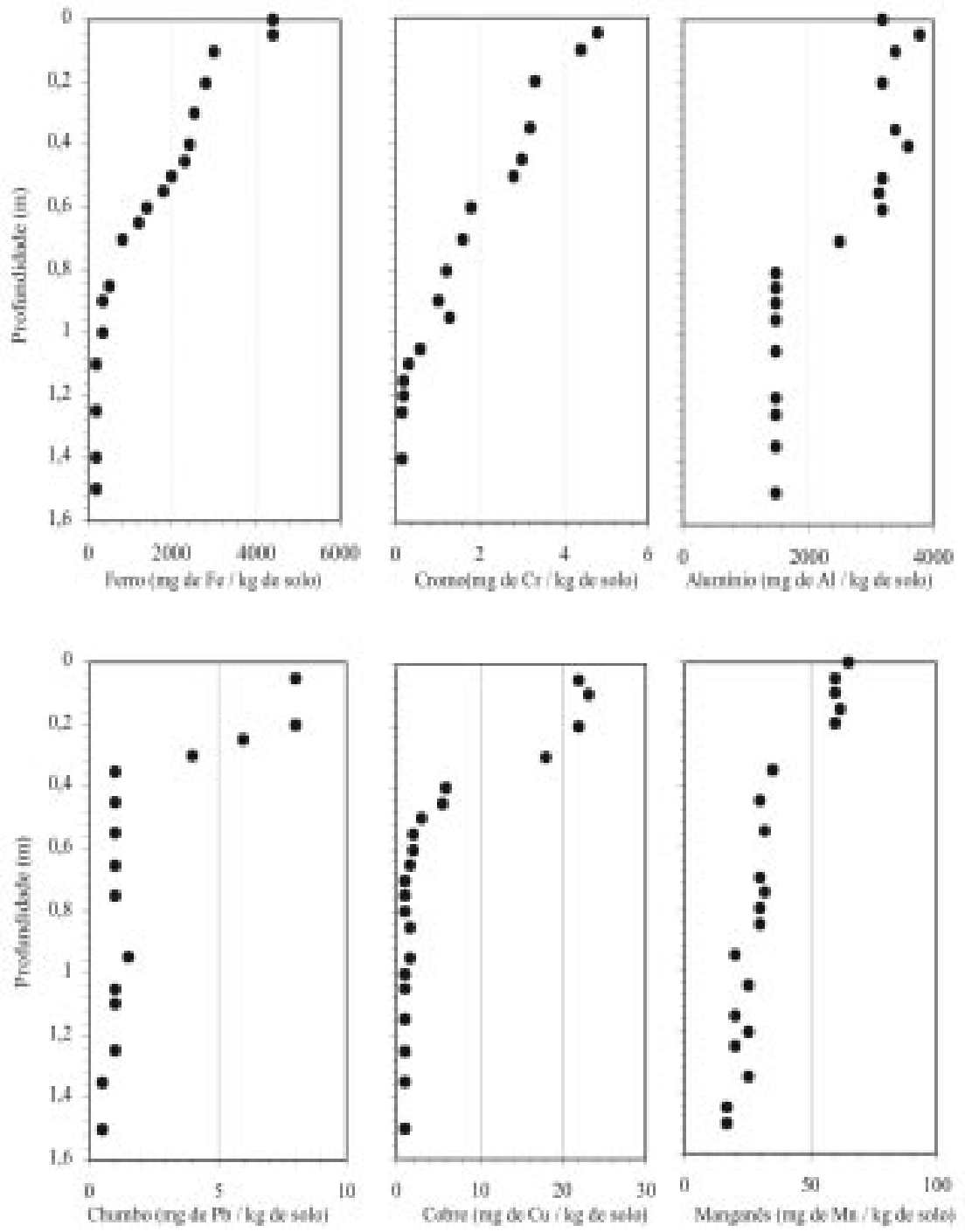

\section{Figura 5 - Perfis da acumulação de Ferro, Cromo, Alumínio, Chumbo, Cobre e Manganês no solo imediatamente inferior à Célula 2 do ARS da Muribeca}

com condutividade hidráulica menor que $1 \times 10^{-8} \mathrm{~cm} / \mathrm{s}$. O transporte de metais pesados através do solo parece não ser apenas determinado pela condutividade hidráulica, mas também pela presença de microorganismos e de substâncias orgânicas. Destaca-se ainda que os dados de profundidade de alcance de saturação pelos metais pesados analisados indicam que o Chumbo, o Cobre e o Manganês foram os metais preferencialmente sorvidos, corroborando os resultados apresentados por Elliot et al. (1986) e por Stevenson (1977), que reportaram preferencial sorção de Chumbo e Cobre por solo natural durante competição com zinco e/ou cádmio.

Após a profundidade de $0,8 \mathrm{~m}$, observa-se valores de concentração destes elementos de até $1 \mathrm{mg} / \mathrm{kg}$, sendo observada a constância nos valores.
O Manganês apresentou um valor máximo de concentração de $60 \mathrm{mg} / \mathrm{kg}$, intermediário entre o Alumínio e os demais metais analisados, e consonante com os valores intermediários de concentração do Manganês no percolado. Na região de menor acúmulo, observa-se valores constantes de concentração de $20 \mathrm{mg} / \mathrm{kg}$.

A comparação entre as Figura 4 e 5 permite ainda verificar que ocorre um maior deslocamento dos metais leves analisados em relação aos metais pesados. Estes resultados corroboram os apresentados por Elliot et al. (1986) e por Fahhar \& Pickering (1977), que verificaram, utilizando ensaios em batelada, maior sorção de metais pesados pelo solo. Estes autores observaram, inclusive, que a sorção preferencial dos metais pesados estava relacionada ao fenômeno de hidratação ou formação de íons complexos. A hidra- tação e/ou complexação dos íons geraria espécies mais facilmente sorvidas devido à afinidade com os grupamentos polares presentes nas estruturas dos argilo-minerais. No entanto, os elevados teores de Sódio em função da profundidade podem estar relacionados com processos de troca catiônica durante a sorção das substâncias orgânicas e/ou metais pesados presentes no percolado, incrementando assim, sua concentração no solo. De fato, a literatura reporta que podem ocorrer processos de troca catiônica de metais leves de solos durante a sorção de substâncias orgânicas e de metais pesados (Weber et al. 2001; Yong et al. 1992).

A comparação da Figura 2 com a Figura 5 evidencia que o solo mais próximo ao lixo apresentou $\mathrm{pH}$ numa faixa de 6 a 7,2, o que facilita a hidratação dos metais, sua precipitação e consequentemente maior acúmulo. Assim, o processo de retenção dos metais pelo solo em estudo pode estar relacionado com fenômenos de adsorção, de troca catiônica, e de precipitação.

Os perfis de acúmulo de metais pesados demostram que estas espécies não alcançaram o embasamento cristalino da região durante 14 anos de operação do aterro. A elevada capacidade de sorção de metais pelo solo juntamente com a sua condutividade hidráulica, evidencia sua capacidade de impermeabilização ao percolado.

\section{CONCLUSÕES}

O percolado do Aterro da Muribeca apresenta elevados teores de DBO, DQO, cloretos e de metais variados. Este líquido é um potencial poluente para o solo e recursos hídricos da região. Neste contexto, a infiltração de água de chuva pela camada de cobertura das células de confinamento é indicada pela estratificação dos parâmetros físico-químicos do chorume com profundidade.

A alteração do $\mathrm{pH}$ do solo adicionada à elevação do teor de voláteis dá clara indicação de infiltração de chorume.

Todos os perfis de concentração dos metais sorvidos pelo solo apresentam clara frente de contaminação em direção ao fundo. Além disso, evidenciou-se uma ampla faixa de variação nas concentraçôes dos metais, que foi identificada como função da concentração de cada espécie no percolado. Ou seja, espécies mais concentradas no percolado apresentaram maior concentração no solo.

Embora o solo apresente baixa superfície específica, $64 \mathrm{~m}^{2} / \mathrm{g}$, possui eleva- 
da capacidade de acúmulo de metais. Cada quilograma de solo foi hábil em sorver no máximo $700 \mathrm{mg}$ de Sódio, $2800 \mathrm{mg}$ de Cálcio, $4500 \mathrm{mg}$ de Ferro, $3800 \mathrm{mg}$ de Alumínio, 8,5 mg de Chumbo, $23 \mathrm{mg}$ de Cobre e $60 \mathrm{mg}$ de Manganês, que está provavelmente relacionado à retenção de material orgânico e/ou elevação de $\mathrm{pH}$, que permite a precipitação de metais pesados.

Os metais pesados apresentaram menor mobilidade no solo que os metais leves analisados. Também foi verificado que o Chumbo, o Cobre e o Manganês foram preferencialmente sorvidos pelo solo em relação ao Ferro, ao Cromo e ao Alumínio.

Os metais pesados preferencialmente sorvidos, e por conseguinte, os que possuíam as menores velocidade médias de saturação, apresentaram valores de aproximadamente $2,3 \times 10^{-2} \mathrm{~m} / \mathrm{ano}$. Estes resultados indicam que o transporte dos metais pesados através do solo do aterro não é predominantemente difusivo, e sim, advectivo-dispersivo, embora o solo apresente uma textura argilosa. Assim, fica claro que o estabelecimento do mecanismo de transporte de metais em solos naturais não é apenas determinado pela condutividade hidráulica, mas também pela presença de microorganismos e de substâncias orgânicas capazes de reter metais pesados.

O solo foi hábil na retenção dos metais e da matéria orgânica, apresentando baixa condutividade hidráulica à água, sendo, portanto, adequado para impermeabilização de fundo da célula.

\section{REFERÊNCIAS}

ABNT - Associação Brasileira de Normas Técnicas. Solo - Determinação do limite de liquidez. NBR 6459, Rio de Janeiro, RJ, 5 p. $1984 a$.

ABNT - Associação Brasileira de Normas Técnicas. Solo-Determinação do limite de plasticidade. NBR 6459, Rio de Janeiro, RJ, 5 p. $1984 b$.

ABNT - Associação Brasileira de Normas Técnicas. Solo - Análise granulométrica. NBR 7181 , Rio de Janeiro, RJ, 13 p. $1984 \mathrm{c}$.

APHA - American Public Health Association. Standard Methods for the examinations of water and wastewater, Washington, 1992.

CHIAN, E.S.K., DeWALLE, F.B. Sanitary landfill leachates and their treatment. Journal of Environmental Engineering Division. v. 102, p. 411-31, 1976.

DANIEL D.E. Geotechnical Practice for Waste Disposal. Chapman and Hall Ed., London, UK, 683 p. 1993.

ELLIOT, H.A., LIBERATI, M.R., HUANG, C.P. Competitive adsorption of heavy metals by soils. Journal of Environmental Quality. v. 15, n. 3, p. 214-19, 1986.
FAHHAR, H., PICKERING, W.F. Influence of clay-solute interactions on aqueous heavy metal ion levels. Water air and soil pollution. v. 8, p. 189-97, 1997.

GENETELLI, E.J., CIRELLO J. Gas and leachate from landfill: formation, collection and treatment. USEPA 600/9-76-004, Cincinnati, USA, 190 p. 1976.

USEPA - United State Enviromental Protection Agency. Gas and leachate from land disposal of municipal solid waste. Summary report. Cincinnati. USA, 21 p., 1975.

HARMSEN, J. Identification of organic compounds in leachate from a waste tip. Water Research. v. 17, p. 699-05, 1983.

JESSBERGER H.L. Waste containment with compacted clay liners. In: Yalcin BA, Daniel, ED (ed). Geoenvironment. ASCE Editors, v.1, p. $463-83,2000$.

JUCÁ, J.F.T., et. al. Ground and surface water contamination due to Municipal Solid Waste in Recife, Brazil. In: PROCEEDINGS OF $2^{\text {th }}$ ENVIRONMENTAL GEOTECHNICS, Osaka, v. I, p. 91-6, 1996.

JUCÁ, J.F.T., OLIVEIRA, F.J.S., AZOUBEL, P.M. Water and wastewater characterizations of the Muribeca municipal solid waste landfill region. In: PROCEEDINGS OF $3^{\text {th }}$ ENVIRONMENTAL GEOTECHNICS, Lisboa, v. I, p. 175-79, 1998.

JUCÁ, J.F.T. E MACIEL, F. J. Permeabilidade ao gás de um solo compactado não saturado. In: $4^{\circ}$ CONGRESSO BRASILEIRO DE GEOTECNIA AMBIENTAL, São José dos Campos, v.1, p. 384-91, 1999.

KUAJARA, O. et al. Environmental monitoring of the north Porto Alegre landfill, Brazil, Water Environmental Research. v. 69, n. 6, p. 117077, 1997.

LEPREVOST, A. Quimica analitica dos minerais. Rio de Janeiro, Editora Livros Técnicos e Científicos, 393 p, 1975.

MITCHELL, J.K. Fundamentals of soil behavior. $2^{\text {th }}$ Edition, New York, John Wiley and Sons Inc., 1993, 437 p.

PALMISANO C., BARLAZ, M. A. Microbiology of solid waste. New York, CRC Press, 240 p, 1996.

QUIGLEY, R.M. et al. Hydraulic conductivity of contaminated natural clay directly below a domestic landfill. Canadian Geotechnical Jounal, v. 24, p. 377-83, 1987.

PEJON, O.J. Mapeamento geotécnico da Folha Piracicaba - SP (escala 1: 100.000). Estudo de aspecto metodológicos, São Carlos, Tese de Doutoramento, EESC-USP, 1992.

RUHL, J.L., DANIEL, D.E. Geosynthetic clay liners permeated with chemical solutions and leachates. Journal of Geotechnical and Geoenvironmental Engineering. v. 123, n. 4, p. 369-81, 1997.

SHACKELFORD C.D., REDMOND, P.L. Solute breakthrough curves for processed kaolin at low-flow rates. Journal of Geotechnical Engineering, v. 121, n. 1, p. 17-32, 1995.

STENVENSON, F. J. Nature of divalent transition metal complexes of humic acids as revealed by a modified potentiometric titration method. Soil Science, v. 123, p. 107, 1977.

TESSIER, A., CAMPBELL, P.G.C., BISSON, M.I.. Sequential extraction procedure for the speciation of particular trace metals. Analytical Chemistry, v. 51, n. 7, p. 844-51, 1979.

WEBER, E.J., COLON D., BAUGHMAN, G.L. Sediment-associated reactions of aromatic amines. 1. Elucidation of sorption mechanisms. Environmental Science and Technology. v. 35, n. 12, p. 2470-75, 1997.

WELTY, J.R., WICKIS, C.E., WILSON, R.E. Fundamentals of momentum, heat, and mass transfer. $3^{\text {th }}$ Edition, New York, John Wiley and Sons, 803 p. 1984.

WHO-World Health Organization International Reference Center for Wastes Disposal. Methods of analysis of sewage sludge solid wastes and compost. Zurich, 1979, $50 \mathrm{p}$.

YASUHARA, A. et al. Determination of organic components in leachates from hazardous waste disposal sites in Japan by gas chromatography mass spectrometry. Journal of Chromatography. v. 774, n. 1-2, 321-32, 1997.

YONG, R.N., MOHAMED, A.M.O., WARKETIN, B. P. Principles of contaminant transport in soils. New York, Elsevier Editory, 327 p. 1992.

Endereço para correspondência:

José Fernando Thomé Jucá Grupo de Resíduos Sólidos (GRS) Universidade Federal de Pernambuco Centro de Tecnologia e Geociências Av. Acadêmico Hélio Ramos, $s / n^{\circ}$ 50740-530 - Recife - PE - Brasil Tel.: (8I) 2 I 26-8224

Fax: (8I) 2 I 26-8222 E-mail: jucah@ufpe.br 